\title{
Suitability of airborne laser scanning for the assessment of forest protection effect against rockfall
}

\author{
Jean-Matthieu Monnet • Franck Bourrier • Sylvain Dupire • Frédéric \\ Berger
}

Received: July 29, 2015 / Accepted: February 10, 2016

\begin{abstract}
Rockfall simulation models are now able to quantify the protective effect of forest with the integration of rock impacts on trees. Those models require spatially-explicit forest characteristics which are costly to acquire in operational conditions. The present study compares rockfall simulation results obtained with different forest input data sources: field data with different levels of spatial detail and two methods based on airborne Lidar data. Three different forest stands are tested with several virtual terrain configurations. When rockfall energies are below $200 \mathrm{~kJ}$, the forest protection effect is significant. For higher energies, it also exists but it is minor compared to the effects of topography and rock volume. For all forest input data sources, the estimated rockfall intensity is within $-13 \%$ and $16 \%$ of the reference value, whereas the frequency is generally over-estimated. Both Lidar methods yield a satisfactory forest protection effect evaluation, but single tree detection tends to under-estimate it. Improvements are possible regarding the spatial heterogeneity of stem density and the diameter distribution by tree species.
\end{abstract}

Keywords Protection forest - Rockfall - RockyFor3D · Airborne laser scanning

This work was funded by the European Commission (project Alpine Space 2-3-2-FR NEWFOR) and by the French Ministry of Defence (program RAPID, project ModTer). We thank Éric Mermin, Pascal Tardif, Nathan Daumergue and David Toe for field data collection.

J.-M. Monnet, F. Bourrier, S. Dupire and F. Berger Université Grenoble Alpes, Irstea, UR EMGR, 2 rue de la Papeterie-BP 76, F-38402 St-Martin-d'Hères, France E-mail: jean-matthieu.monnet, franck.bourrier, sylvain.dupire, frederic.berger@irstea.fr

\section{Introduction}

The protective effect of forests against rockfall hazard has been known for a long time. However research on the interactions between tree stands and falling blocks only dates back to the 1980's. The effect of forests was integrated into empirical (Ciabocco et al 2009, Jancke et al 2009, Bigot et al 2009) or process-based lumpedmass rockfall models (Stoffel et al 2005, Dorren et al 2006: Radtke et al 2014). Both types of model present efficient computational times and global accounting of forest effects. In the more advanced 3-D approaches, trees are individually integrated into the site model. This requires to build a virtual forest that faithfully represents the real forest from the rockfall perspective.

Nowadays, forest inventories are mainly based on sampling of field plots. On each field plot all trees above a determined diameter are measured, and their positions are sometimes recorded. Those statistical inventories provide at the forest level estimates of stand parameters such as basal area (total area occupied by the cross-sections of tree trunks at $1.3 \mathrm{~m}$ height), stem density, mean diameter, top height or growing stock. It is not possible to map the spatial variation of those parameters except for very dense sampling in forests with low heterogeneity. Unfortunately, the topography in mountainous environments enhances both inventory costs and the variability of forest stands. A few decades ago, some full-census inventories were still implemented. The species-specific diameter distribution of trees was available for all forest compartments, i.e. surfaces of a few hectares. Inventories of all trees with their positions on surfaces larger than 0.25 ha are now rare and usually dedicated to training or research purposes. The information available to managers of protection forests is only partial as the spatial patterns and distributions of 
values (e.g. diameters) and species are rarely available at fine resolution for whole forests.

Airborne laser scanning, or Lidar, is a remote sensing technique which has proven its efficiency for forest inventory, both at the stand and tree levels. At the stand level, the so-called area-based method is based on the calibration of empirical relationships between stand parameters and descriptors of the Lidar point cloud, also called "metrics" (Næsset 2002). The relationships are calibrated thanks to a sample of field plots similar to those used in statistical inventories. This method has been tested in many forest contexts and is now used in operational forest inventories (Hollaus et al 2009; White et al 2013, Holopainen et al 2014). In mountainous forests, the accuracy at a spatial resolution of around $25 \mathrm{~m}$ is approximately $15 \%$ for basal area, $12 \%$ for mean diameter, $5 \%$ for top height and $35 \%$ for stem density (Heurich and Thoma 2008, Munoz et al 2015. Monnet et al 2015). Even tough the estimates are theoretically unbiased (McRoberts 2010), the error can be locally important due to the high variability of tree shapes and stand structures.

If point density of the Lidar data is sufficient to describe the shape of individual trees, single tree detection methods can be implemented. Many algorithms have been proposed to extract trees in the point cloud or the derived canopy height model. A few benchmarks (Kaartinen et al 2012, Vauhkonen et al 2012, Eysn et al 2015) have been published and all highlight the main limitation of this method, which is the low detection rate of suppressed and co-dominant trees. Moreover, the detection performance is difficult to quantify without field data, as it depends on the algorithm parametrisation and on the stand structure. The estimation of stand-level parameters from the extracted trees is thus troublesome, and area-based methods were shown to have better accuracies for the estimation of diameter and number of stems (Peuhkurinen et al 2011). Combinations of both methods have also been tested. Lindberg et al (2010) and Xu et al (2014) calibrated the detected tree list with the distribution estimated by the area-based approach. Breidenbach et al (2010) used an area-based method applied to the detected segments in order to estimate the real number of trees inside each segment. For timber production purposes, it is important to have unbiased estimates of stand parameters, but the spatial pattern of trees positions at the trees group level (surface around 10 ares) is of less importance. However, when modelling 3-D rockfall trajectories, the combination of topographical features with the position of the largest trees, the presence of canopy gaps or unforested channels may have a major effect on the spatial distribution of trajectories and on their inten- sity and frequency. The estimation errors and spatial resolution of Lidar prediction models may thus have an important effect on the evaluation of rockfall protection effect at the stand level.

The objective of this study is to compare the suitability of different field and Lidar-based inventories for the evaluation of forest protection effect against rockfall at the stand level. The area-based method and a single tree detection algorithm are tested separately and in combination. Simulated rocks trajectories are compared in terms of rockfall event frequency and intensity for three different forest stands of surface 0.25 to 1 ha, depending on the method used for forest mapping. Section 2 presents the forest and Lidar datasets. Section 3 details the steps of the workflow and section 4 the obtained results. A discussion follows in section 5

\section{Material}

Three study areas located in the French Alps are considered: Saint-Paul, Saint-Agnan, and Valdrôme. For each study area three types of data are available.

- Airborne Lidar data.

- One large forest plot (surface 0.25 to 1 ha) with full inventory of positions, diameters, and species of trees.

- Forest inventory plots of smaller surface (314 to $707 \mathrm{~m}^{2}$ ), where trees have been inventoried and stand parameters calculated.

\subsection{Lidar data}

Lidar data were acquired over the three study areas with a RIEGL LMS-Q560 scanner carried by an air plane. Flight height was $600 \mathrm{~m}$ above ground and the resulting footprint was $0.3 \mathrm{~m}$. The pulse repetition frequency was $170 \mathrm{kHz}$ in Saint-Agnan and Valdrôme, and 120 in Saint-Paul. The data were acquired in Aug. 2009 in Saint-Paul, Sept. 2010 in Valdrôme and Sept. 2010 and Aug. 2011 in Saint-Agnan. Echoes were extracted from the binary acquisition files and georeferenced with the RIEGL software suite. The contractor also classified the resulting point cloud into ground and non-ground echoes using the TerraScan software. Lidar pulse density is approximately $10 \mathrm{~m}^{-2}$. Lidar point cloud transects are displayed on Fig. 1

\subsection{Large forest plot data}

Field data is available for one large plot in each study area. The three stands display different structures and 

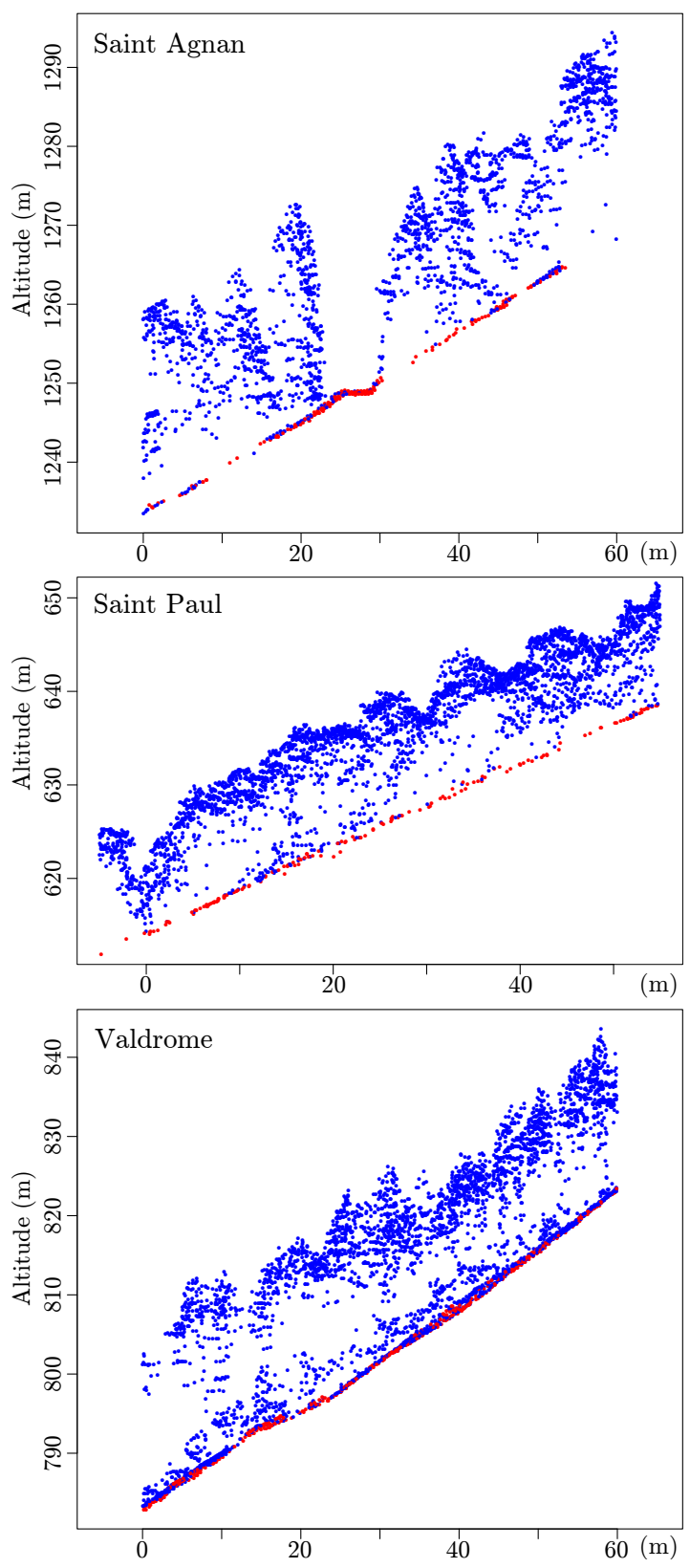

Fig. 1 Lidar point cloud transects along the slope direction for each forest site. Points classified as ground are red, vegetation points are in blue. Transect width is $5 \mathrm{~m}$, except for Saint Paul (2 m)

species, and are located in rockfall hazard areas. Trees positions, diameters and species were measured for all trees with diameter at breast height (DBH) larger than $7.5 \mathrm{~cm}$ ( $5 \mathrm{~cm}$ in Saint-Paul). Intermediate markers are positioned in the field and geolocated with GNSS receivers with differential post-correction. Trees are positioned relatively to the nearest marker using a compass and a clisimeter mounted on a tripod and a laser rangefinder. The accuracy of tree position relatively to the marker is expected to be around $0.5 \mathrm{~m}$. Diameters
Table 1 Description of large plots.

\begin{tabular}{lccc}
\hline Site & Saint-Agnan & Saint-Paul & Valdrôme \\
\hline Structure & Uneven-aged & Coppice & Even-aged \\
\hline $\begin{array}{l}\text { Surface } \\
\left(\mathrm{m}^{2}\right)\end{array}$ & $85 \times 120$ & $50 \times 50$ & $50 \times 200$ \\
\hline $\begin{array}{l}\text { Diameter thres- } \\
\text { hold }(\mathrm{cm})\end{array}$ & 7.5 & 5 & 7.5 \\
\hline $\begin{array}{l}\text { Basal area } \\
\left(\mathrm{m}^{2} \cdot \mathrm{ha}^{-1}\right)\end{array}$ & 32.5 & 31.2 & 45.5 \\
\hline $\begin{array}{l}\text { Diameter }(\mathrm{cm}) \\
\left(\mathrm{mean}^{\mathrm{n}} \mathrm{sd}\right)\end{array}$ & $30.1 \pm 15.7$ & $12.5 \pm 8.0$ & $22.3 \pm 8.3$ \\
\hline $\begin{array}{l}\text { Stem density } \\
\left(\mathrm{ha}^{-1}\right)\end{array}$ & 357 & 1800 & 1025 \\
\hline
\end{tabular}

are measured using a ruban tape. A Vertex III hypsometer is used for height measures. Plots statistics are presented in Table 1 .

The Saint-Agnan plot located next to the Réserve Naturelle des Hauts-Plateaux du Vercors $\left(44.8769^{\circ} \mathrm{N}\right.$, $5.4295^{\circ} \mathrm{E}$ ) has a 1 ha surface. It was inventoried in July, 2010. It is located in a protection forest at $1250 \mathrm{~m}$ above sea level, on a hillside oriented to the west, with a $32^{\circ}$ slope. A forest road crosses the middle of the plot along the north-south direction. The stand has an unevenaged structure, and is mainly constituted of silver fir (Abies alba, $53 \%$ of stems) and beech (Fagus sylvatica, $40 \%$ of stems). Heights were measured for all trees.

The Saint-Paul plot is located on the eastern slope of the Vercors $\left(45.0830^{\circ} \mathrm{N}, 5.6484^{\circ} \mathrm{E}\right)$ at $630 \mathrm{~m}$ above sea level. The forest is a coppice stand constituted of Italian maple (Acer opalus, $25.8 \%$ of stems), common hazel (Corylus avellana, 25.6\%), common whitebeam (Sorbus aria, 23.6\%) and pubescent oak (Quercus pubescens, $16.9 \%)$. No heights were measured.

The Valdrôme plot is situated across a west facing hillside in the southern Vercors $\left(44.5336^{\circ} \mathrm{N}, 5.5625^{\circ} \mathrm{E}\right)$, under a small cliff. Its surface is 1 ha. It is an example of European black pine (Pinus nigra) stands planted during the afforestation program to mitigate erosion. The lower part of the hillside has better site quality and the stand was thinned in 1986 and 2006 (ONF 2012). Trees have grown larger than in the upper part, where stand density is also larger. Heights were measured in three transects including a total of 362 trees.

\subsection{Forest inventory data}

The field protocol is the same for Saint-Paul and SaintAgnan. Plot positions are sampled in the study area covered by Lidar data. The plot centre is recorded on 
Table 2 Description of inventory data. For each parameter, the mean value is on the first row, the range is on the second.

\begin{tabular}{lccc}
\hline $\begin{array}{l}\text { Site (number } \\
\text { of plots) }\end{array}$ & $\begin{array}{c}\text { Saint-Agnan } \\
(96)\end{array}$ & $\begin{array}{c}\text { Saint-Paul } \\
(31)\end{array}$ & $\begin{array}{c}\text { Valdrôme } \\
(23)\end{array}$ \\
\hline $\begin{array}{l}\text { Basal area } \\
\left(\mathrm{m}^{2} . \mathrm{ha}^{-1}\right)\end{array}$ & $\begin{array}{c}40.2 \\
15.7-99.2\end{array}$ & $\begin{array}{c}34.2 \\
4.6-59.7\end{array}$ & $\begin{array}{c}44.7 \\
26.8-68.4\end{array}$ \\
\hline $\begin{array}{l}\text { Mean diameter } \\
(\mathrm{cm})\end{array}$ & $\begin{array}{c}24.8 \\
14.7-75.5\end{array}$ & $\begin{array}{c}14.5 \\
8.3-22.7\end{array}$ & $\begin{array}{c}24.5 \\
16.1-31.0\end{array}$ \\
\hline $\begin{array}{l}\text { Std deviation } \\
\text { diameter }(\mathrm{cm})\end{array}$ & 13.1 & 7.6 & 6.9 \\
\hline $\begin{array}{l}\text { Stem density } \\
(\text { ha }\end{array}$ & $6.2-28.1$ & $3.0-15.0$ & $4.2-11.7$ \\
\hline $\begin{array}{l}\text { Lidar pulse } \\
\text { density }\left(\mathrm{m}^{-2}\right)\end{array}$ & 510 & 1710 & 970 \\
\hline
\end{tabular}

the field by a GNSS receiver with differential correction. The diameter and species of all live trees within 10 and $15 \mathrm{~m}$ horizontal distance from the plot centre, with DBH above 5 and $7.5 \mathrm{~cm}$, respectively for Saint-Paul and Saint-Agnan, are recorded. From the tree data, the mean and standard deviation of diameters, and stem density are computed.

In the Saint-Paul study area, 31 circular field plots were inventoried in 2009 (Monnet et al 2010a). Ten tree heights were measured on each plot, with sampling probability proportional to stem basal area. In Saint-Agnan, 96 plots were inventoried between 2011 and 2012, and all heights were measured except for 24 plots. In Valdrôme, such data are not available. A dataset was thus simulated by extracting 23 circular plots of $12.5 \mathrm{~m}$ radius inside the large plot. Forest inventory plots statistics are summarised in Table 2.

\section{Methods}

\subsection{Rockfall modelling}

The software RockyFor3D is a rockfall simulation model that calculates trajectories of single, individually falling rocks, in three dimensions (Dorren et al 2005). The model combines physically-based algorithms with stochastic approaches. The rocks trajectories are considered as sequences of classical parabolic free falls through the air and rebounds on the slope surface. Impacts against trees are also explicitly modelled. The required input data consist of a set of rasters which define slope surface, forest and rock characteristics, and topography (Dorren 2015). Spatial resolution of the raster input data is $2 \mathrm{~m}$ in this study. Each time a simulated rock surpasses or rebounds in a given raster cell, statistics of the rock trajectory in that cell are recorded.

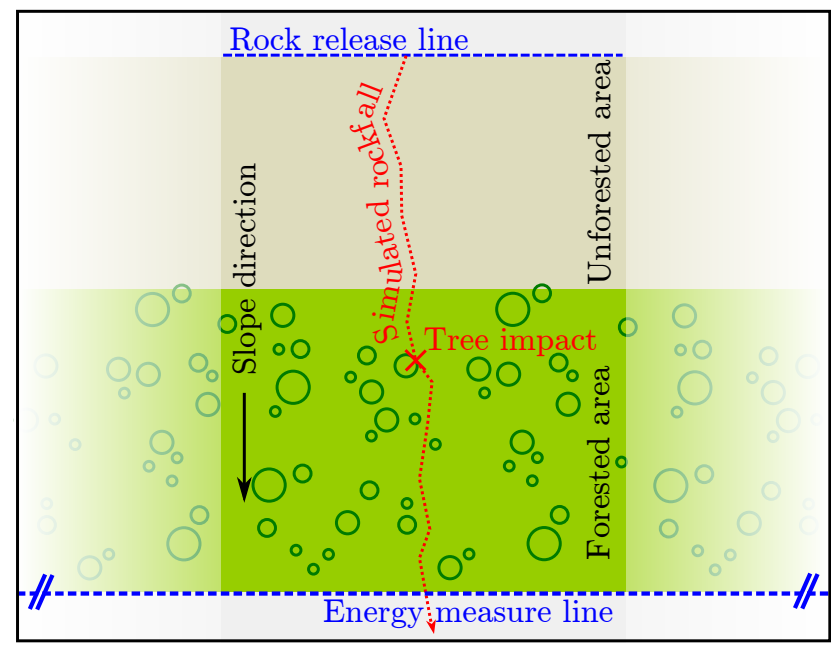

Fig. 2 Simulation scheme

Simulations are held on archetypal virtual terrains to focus on the effect of forest inputs in rockfall assessment. To assess the effect of forest inputs for different terrain types and rock sizes, the following combinations are considered: $35^{\circ}$ slope and rock volume of $0.5,1$ or $2 \mathrm{~m}^{3}$, and soil types $a$ or $b$. Soil type $a$ is a compact soil with rock fragments, the roughness of the surface is expressed as obstacles with heights in the slope direction of $0.05 \mathrm{~m}, 0.1 \mathrm{~m}$ and $0.2 \mathrm{~m}$ for $70 \%, 20 \%$ and $10 \%$ of the surface. Soil type $b$ is a soft soil with no roughness, i.e. obstacles with nil heights on the whole surface. Simulations are also implemented with a slope of $30^{\circ}$ for both soil types and only for a rock volume of $1 \mathrm{~m}^{3}$. A total of eight combinations of slope, rock size and soil type values are tested.

Spherical rocks with a density of $2600 \mathrm{~kg} \cdot \mathrm{m}^{-3}$ are released from five meters height along a contour line (Fig. 2). Their velocity increases across an unforested area of $50 \mathrm{~m}$, which ensures that the maximal velocity is attained (Perret et al 2004). Then they enter a forest patch where tree impacts might slow down or even stop some rocks. The forest input data are summarised into a file with the trees positions and diameters. The percentage of coniferous trees in each pixel is supplied as a raster file. For the convenience of forest input data computations, the Saint-Agnan plot is cropped to $120 \times 80 \mathrm{~m}^{2}$, Saint-Paul to $48 \times 48 \mathrm{~m}^{2}$ and Valdrôme to $48 \times 192 \mathrm{~m}^{2}$. This ensures that the plots can be divided into integer numbers of pixels (see next subsection). The length of the forest patch in the slope direction is $80 \mathrm{~m}$ in Saint-Agnan, and $48 \mathrm{~m}$ in SaintPaul and Valdrôme. Forest patch width is respectively 120,48 , and $192 \mathrm{~m}$. 


\subsection{Forest input data scenarios}

Five scenarios are considered for the creation of the forest patch input data. A sixth scenario corresponds to simulations without forest.

1. FieldTree: tree-level positions and diameters are measured on the field;

2. FieldArea: stem number and diameter distribution are known from field data at coarse spatial resolution (around $0.25 \mathrm{ha}$ );

3. LidarTree: trees positions and heights are detected in Lidar data;

4. LidarArea: stem number and diameter distribution are estimated by Lidar models at medium spatial resolution (around $0.04 \mathrm{ha}$ );

5. LidarCombi: detected trees positions are combined with stem number and diameter distribution estimates;

6. None: no forest is considered.

The workflow for forest input data creation is presented in Fig. 3 .

\subsubsection{Tree-level field data (FieldTree scenario)}

This scenario corresponds to the ground truth data. The large forest plot data available in each study area are used for this scenario. Using this plot, the positions and diameters are known, and the coniferous percentage input is a raster image of $2 \mathrm{~m}$ resolution computed by retaining in each pixel the proportion of coniferous trees among trees located inside this pixel.

\subsubsection{Area-level field data (FieldArea)}

In this scenario the spatial distribution of trees is not known precisely and the diameter distribution is modelled from its mean and standard deviation. It is meant to correspond to the usual practice of statistical inventory, but with a high plot density which would enable to estimate the mean diameter and its standard deviation in surfaces of approximately 0.25 ha. The large plot is divided in large square pixels of $40 \mathrm{~m}$ in SaintAgnan and $48 \mathrm{~m}$ in Saint-Paul and Valdrome, in order to have an integer number of pixels for the forest patch. The mean and standard deviation of diameter are calculated for these large pixels from the field inventory, as well as the coniferous percentage and stem density.

Inside each large pixel, trees positions are randomly generated with uniform probability distribution so that stem density is respected. Trees diameters are generated using a Gamma distribution respecting the mean and standard deviation of diameters computed from the field data in each large pixel. The mean coniferous percentage is also computed in each large pixel.

\subsubsection{Tree-level Lidar data (LidarTree)}

This scenario is based on the extraction of trees positions and heights from the Lidar data. An algorithm based on local maximum filtering (Monnet et al 2010b; Eysn et al 2015) is applied to the three large plots. The detection outputs are the positions and heights of the local maxima of the canopy height model computed from the Lidar data. Those local maxima should correspond to the apices of the dominant trees. In order to estimate the corresponding diameters and the coniferous percentage, field data is still required. A linear regression is fitted between the natural logarithm of $\mathrm{DBH}$ and the measured height for a random sample of $10 \%$ of the field trees. This relationship is then applied to the detected heights in order to calculate the diameters. The coniferous percentage is set to the average value of the whole plot according to the field data.

\subsubsection{Area-based Lidar data (LidarArea)}

For each site, the forest inventory data are used to calibrate regression models between Lidar metrics and the forest stand parameters: mean DBH, DBH standard deviation and stem density (Monnet et al 2010b, 2015). Statistics about models accuracy obtained in leave-oneout cross-validation are presented in Table 3 .

The models are then applied to the point cloud contained in the plots divided in medium square pixels of $20 \mathrm{~m}$ width in Saint-Agnan, $16 \mathrm{~m}$ in Saint-Paul and $24 \mathrm{~m}$ in Valdrôme. Medium pixel size is chosen to be similar to calibration plot size and to ensure that the large plot is divided into an integer number of pixels. The positions and diameters of trees are then generated using the same procedure as for the FieldArea scenario, except for the different resolution and the fact that stem number, and the mean and standard deviation of diameters are estimated from the Lidar data. The coniferous percentage input is the same as for LidarTree, i.e. the average value over the whole plot.

\subsubsection{Combined tree-area Lidar data (LidarCombi)}

This scenario aims at combining both Lidar methods to take advantage of the spatial information of tree detection, of the theoretically unbiased estimates of diameter by the area-based method, and of the forest cover information provided by the Lidar canopy height model. The procedure starts with the same diameter values as 


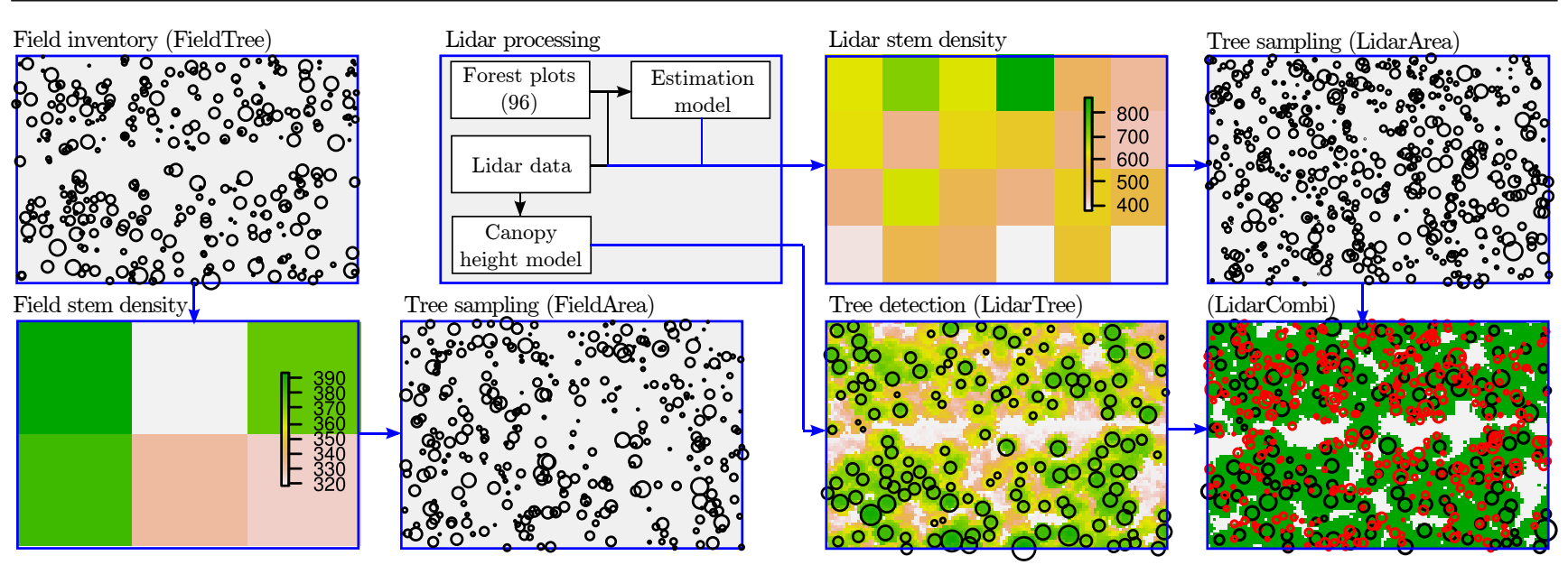

Fig. 3 Workflow for the production of forest input data for the five scenarios in Saint-Agnan $\left(120 \times 80 \mathrm{~m}^{2}\right)$. Dots represent the positions of input trees, with size proportional to diameter. Red dots in LidarCombi are the sampled positions, while black dots are the detected positions. Background in LidarTree is the canopy height model and the forest mask in LidarCombi. Other backgrounds are the average stem density in pixel, but for the tree sampling the mean and standard deviation of diameter are also used

Table 3 Statistics of the Lidar estimation models: adj- $\mathrm{R}^{2}$ of linear regression, root mean square error and its coefficient of variation obtained in cross-validation. No model has a significant bias in cross-validation $(p>0.7$ in two-tailed Wilcoxon test).

\begin{tabular}{lcccc}
\hline $\begin{array}{l}\text { Site (plot } \\
\text { number) }\end{array}$ & Parameter & adj-R & $R M S E$ & $\begin{array}{c}C V_{R M S E} \\
(\%)\end{array}$ \\
\hline Saint & DBH & 0.78 & $8.6 \mathrm{~cm}$ & 34.5 \\
Agnan & sd(DBH) & 0.72 & $2.6 \mathrm{~cm}$ & 19.6 \\
$(96)$ & $\mathrm{N}$ & 0.79 & $220 \mathrm{ha}^{-1}$ & 26.6 \\
\hline Saint & $\mathrm{DBH}$ & 0.64 & $2.3 \mathrm{~cm}$ & 15.8 \\
Paul & $\mathrm{sd}(\mathrm{DBH})$ & 0.77 & $1.5 \mathrm{~cm}$ & 19.9 \\
$(31)$ & $\mathrm{N}$ & 0.59 & $390 \mathrm{ha}^{-1}$ & 22.5 \\
\hline Valdrôme & $\mathrm{DBH}$ & 0.71 & $2.3 \mathrm{~cm}^{2}$ & 9.3 \\
$(23)$ & $\mathrm{sd}(\mathrm{DBH})$ & 0.70 & $0.8 \mathrm{~cm}^{-1}$ & 11.4 \\
& $\mathrm{~N}$ & 0.70 & $260 \mathrm{ha}^{-1}$ & 27.3 \\
\hline
\end{tabular}

obtained in LidarArea scenario, but sampled stem positions are constrained to be located inside areas where the canopy height model has values above $5 \mathrm{~m}$, i.e. trees cannot be created in canopy gaps according to the Lidar data. Finally, the trees are sorted by decreasing diameters, and detected LidarTree maxima are sorted by decreasing heights. The coordinates of the sampled trees are replaced by the coordinates of the detected trees with same ranks in the lists. LidarArea trees with no corresponding maxima are left at their sampled coordinates. Detected maxima with no corresponding $L i$ darArea trees are removed. This case may happen, e.g. when the area-based method underestimates the stem number and the tree detection yields many false positives (detected maxima which do not correspond to any existing tree).

\subsection{Rockfall simulations}

10000 rockfall trajectories are simulated for each twometer-wide pixel located on the release contour line. The number and the kinetic energy of passing rocks is recorded at the measure line, which is the contour line immediately below the forest patch. To avoid border effects, forest patches are laterally duplicated. The release line width is equal to the width of the forest patch and the measure line covers the whole width (patch plus lateral buffers, Fig. 2). The forest protection effect on rockfall frequency is evaluated by computing the reach probability (number of rocks that reach the measure line divided by the total number of simulated trajectories). The effect on intensity is computed as the $95^{\text {th }}$ percentile of the kinetic energy of rocks that reach the measure line. The $95^{\text {th }}$ percentile is chosen because it achieves a satisfactory balance between the objective to evaluate the protection effect with regards to the most extreme events, and the stability of the estimator considering the number of simulations.

The number of levels is four for slope and rock volume $\left(35^{\circ} \times\{0.5,1,2\} \mathrm{m}^{3}\right.$ and $\left.30^{\circ} \times 1 \mathrm{~m}^{3}\right)$, two for soil type, three for study area and six for forest input data scenarios, which yields a total of 144 combinations.

As the tree sampling is done before the trajectory simulations in the -Area scenarios, the obtained spatial and diameter distribution pattern might impact the rockfall frequency and intensity results. To estimate the variability due to this step, 30 repetitions of $10000 \mathrm{sim}-$ ulations are done for the combination of $35^{\circ}$ slope, $1 \mathrm{~m}^{3}$ volume and soil type $b$ in the three study areas and for all input scenarios. 

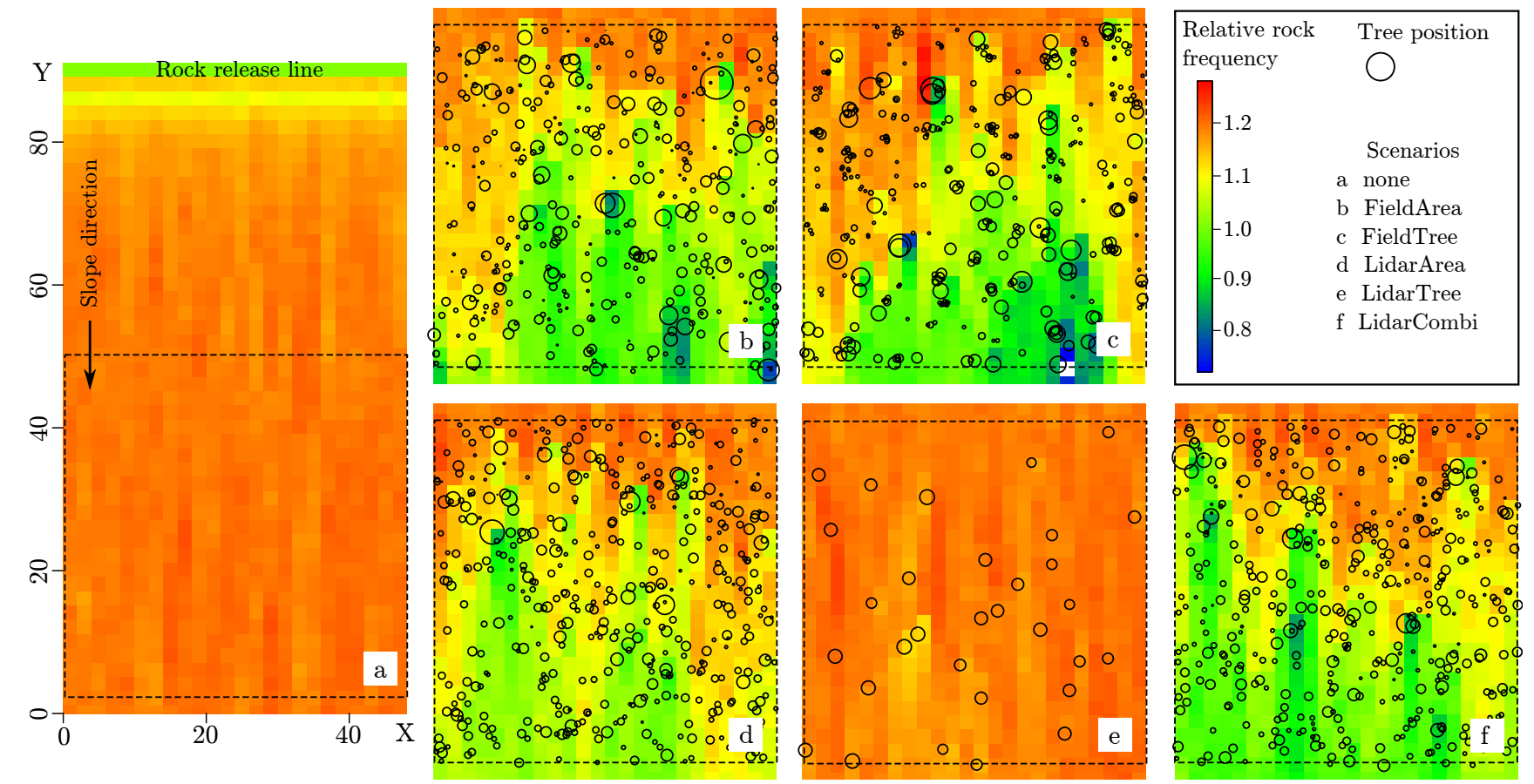

Fig. 4 Illustration of simulation results in Saint-Paul for soil type $a, 1 \mathrm{~m}^{3}$ rock volume and $35^{\circ}$ slope: relative rockfall frequency (number of trajectories passing in each cell divided by the number of simulated rockfalls for each departure cell). Values can be larger than 1 because of lateral deviations which cause trajectories to cross two cells on the same contour line. The full extent is displayed for the None scenario and corresponds to the scheme on Fig. 2. For other scenarios only the forest extent is displayed. Tree diameters are exagerated for better visualisation

\section{Results}

Fig. 4 illustrates rockfall simulation results. Difference in the trees spatial distribution for the five forest input scenarios and its effect on rockfall passage frequency are illustrated in the case of Saint-Paul, with soil type $a, 1 \mathrm{~m}^{3}$ rock volume and $35^{\circ}$ slope.

\subsection{Lidar estimation results}

The accuracy assessment of tree detection method is based on an automated procedure (Monnet et al 2010b). In Saint-Agnan, 136 (38.1\%) of the 357 trees are correctly detected, with 18 false positives. In Saint-Paul, 30 $(11.9 \%)$ are detected, with 6 false positives. In Valdrôme, $499(48.7 \%)$ are detected, with 43 false positives. As usual with tree detection, dominant trees are well detected whereas trees in the lower layers are often missed (Fig. 5). The height is over-estimated by Lidar, with an average of $0.2 \mathrm{~m}$ in Valdrôme, $0.6 \mathrm{~m}$ in Saint-Paul and $1.4 \mathrm{~m}$ in Saint-Agnan. Standard deviation of errors is $1.5 \mathrm{~m}$ for all plots. Linear regression with measured height $h$ as a function of the Lidar height $h_{l}$ is $h=0.93 \times h_{l}+0.49$ for Saint-Agnan $\left(\mathrm{R}^{2}=0.85\right)$, $h=0.90 \times h_{l}+1.87$ for Saint-Paul $\left(\mathrm{R}^{2}=0.45\right)$ and $h=0.90 \times h_{l}+1.79$ for Valdrôme $\left(\mathrm{R}^{2}=0.81\right)$. Heights
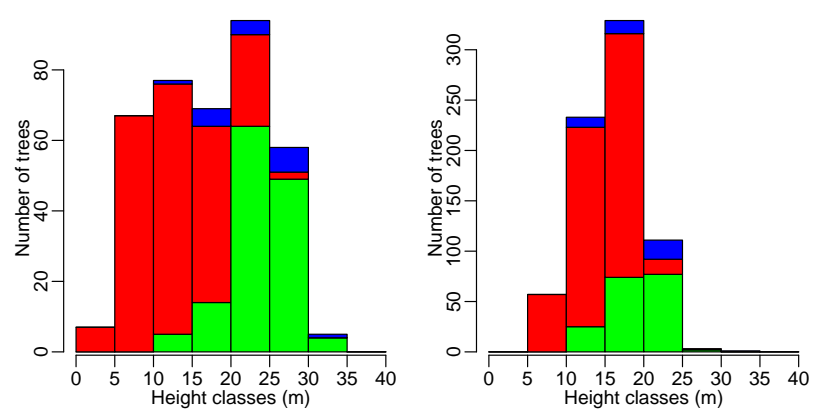

Fig. 5 Number of detected trees (green), omission (red) and commission (blue) errors, in different height classes for the Saint-Agnan (left) and Valdrôme (right) plots

of tall trees tend to be over-estimated, whereas small trees are rather under-estimated.

Regarding the Lidar area-based method, the mean and standard deviation of the diameter are generally under-estimated in Saint-Agnan and Saint-Paul. On the contrary, stem density is over-estimated (Table 4). In Valdrôme mean diameter is also under-estimated but the error for the other parameters is close to zero. 
Table 4 Statistics on the errors of the Lidar estimation models at the pixel level. Mean and standard deviation of $\mathrm{DBH}$ are in $\mathrm{cm}$, stem density is in $\mathrm{ha}^{-1}$. Bias significance: ${ }^{*} p<0.05,{ }^{* *} p<0.01,{ }^{* * *} p<0.001$ in a two-tailed Wilcoxon test.

\begin{tabular}{lccc}
\hline Site (Pixel number) & Parameter & Bias & Std dev. \\
\hline \multirow{2}{*}{ Saint-Agnan (24) } & mean(DBH) & $-1.7^{*}$ & 4.7 \\
& sd(DBH) & $-1.8^{* * *}$ & 2.4 \\
& stem density & $190^{* * *}$ & 120 \\
\hline \multirow{2}{*}{ Saint-Paul (9) } & mean(DBH) & -1.0 & 2.4 \\
& sd(DBH) & $-2.7^{* * *}$ & 1.2 \\
& Stem density & 260 & 430 \\
Valdrôme (16) & mean(DBH) & -1.2 & 2.5 \\
& sd(DBH) & 0.5 & 1.2 \\
& Stem density & -5 & 260 \\
\hline
\end{tabular}

\subsection{Rockfall simulations variability}

The coefficient of variation (standard deviation of values divided by their mean) of the reach probability $R P$ and the $95^{\text {th }}$ percentile of energy $E_{95}$ for the 10000 repetitions are presented in Table 5. The variability for all statistics is around $0.1 \%$ in the case of the None scenario, where only the rebound modelling includes variability. When trees deflect the rockfall trajectories, the variability slightly increases, with values between 0.14 and $0.31 \%$ for the FieldTree and LidarTree scenarios. In those cases, the trees positions are the same for all repetitions. Compared to the None scenarios, the additional variability is due to more complex trajectories because of tree impacts. When the trees positions are sampled before each repetition (FieldArea and $\mathrm{Li}$ darArea scenarios), the variability is between 0.74 and $1.57 \%$ for $E_{95}$ and between 3.22 and $8.25 \%$ for $R P$. The LidarCombi has similar values as the LidarArea, except in Valdrôme where the variability is smaller.

Table 5 Coefficient of variation $(\%)$ of the $95^{\text {th }}$ percentile of rock energy $E_{95}$ and of the reach probability $R P$ for 30 repetitions of 10000 simulations in the case of $30^{\circ}$ slope, soil type $b$ and $1 \mathrm{~m}^{3}$ rock volume.

\begin{tabular}{lcccccc}
\hline Forest input & \multicolumn{2}{c}{ Saint-Agnan } & \multicolumn{2}{c}{ Saint-Paul } & \multicolumn{3}{c}{ Valdrôme } \\
scenario & $E_{95}$ & $R P$ & $E_{95}$ & $R P$ & $E_{95}$ & $R P$ \\
\hline None & 0.10 & 0.00 & 0.25 & 0.00 & 0.10 & 0.00 \\
FieldTree & 0.22 & 0.15 & 0.31 & 0.14 & 0.24 & 0.17 \\
FieldArea & 0.88 & 4.31 & 1.57 & 8.25 & 0.74 & 3.22 \\
LidarTree & 0.23 & 0.11 & 0.19 & 0.08 & 0.16 & 0.10 \\
LidarArea & 1.20 & 4.97 & 1.00 & 6.19 & 0.75 & 3.26 \\
LidarCombi & 1.20 & 4.88 & 1.13 & 5.12 & 0.46 & 2.57 \\
\hline
\end{tabular}

\subsection{Forest protection effect}

\subsubsection{Comparison with and without forest}

The forest protection effect is evaluated as the ratio of the $R P$ and $E_{95}$ values obtained in the FieldTree and None scenarios. Fig. 6 displays the ratios for all three sites as well as the absolute values of $E_{95}$ and $R P$.

With the $30^{\circ}$ slope, soil $b$, and $1 \mathrm{~m}^{3}$ volume and with $35^{\circ}$ slope, soil $b$, and $0.5 \mathrm{~m}^{3}$ volume, $E_{95}$ is between 56 and $105 \mathrm{~kJ}$ while $R P$ is in the range $0.038 \%$ to $6 \%$. On the one hand, $E_{95}$ is hardly modified when the forest is taken into account, with a ratio between 0.97 and 1.06 (except for Valdrôme with $30^{\circ}$ slope, soil $b$ ). On the other hand, $R P$ is decreased by the forest, with ratios between 0.09 and 0.21 , i.e. rockfall frequency is divided by 5 to 10 .

For the other cases, $R P$ in unforested terrain is almost always equal to $100 \% . E_{95}$ is between 239 and $2060 \mathrm{~kJ}$. The values are mostly influenced by the terrain and rock volume, the impacts on trees only have a secondary effect. Differences in $E_{95}$ for unforested scenario are due to the longer runout length in SaintAgnan compared to the other sites. The $E_{95}$ ratio is between 0.80 and 0.93 whereas for $R P$ it is between 0.27 and 0.98 . Sorted by increasing value of $E_{95}$, the combinations (slope, soil, volume) are approximately : $(35, b, 1),(35, a, 0.5),(30, a, 1),(35, a, 1),(35, b, 2)$ and $(35, a, 2)$. When $E_{95}$ increases, the $R P$ ratio also increases: the higher the energies, the lowest the effect of forest on the reach probability. For a given combination of terrain and volume, the forest effect on $E_{95}$ is higher in Valdrôme and lower in Saint-Paul. For $R P$ the effect is higher in Saint-Agnan and lower in Saint-Paul.

\subsubsection{Influence of forest input data}

The ratios between $E_{95}$ calculated for each forest input scenario and the value for the FieldTree scenario are calculated and displayed on Fig. 77. Comparatively to the FieldTree scenario, the other forest input data yield relative errors in the estimation of $E_{95}$ between $-13 \%$ and $16 \%$. For $R P$ the relative error is between $-75 \%$ and $220 \%$, so that the largest error is an overestimation of $R P$ with forest compared to the FieldTree reference. The ratio of $E_{95}$, and to a lesser extent, $R P$ should be handled with care in the case $(30, b, 1)$ because of the low number of rocks that go through the whole forest patch (71 to 1129 ).

For all sites, the LidarTree scenario yields an underestimation of the forest protection effect, both for $E_{95}$ and $R P$ (except for the combination $30^{\circ}, b, 1$ in Saint-Agnan) 


\begin{tabular}{|l|}
\hline Site \\
口 Saint-Agnan \\
○ Saint-Paul \\
$\Delta$ Valdrome \\
Slope - soil \\
$-30-\mathrm{a}$ \\
$-30-\mathrm{b}$ \\
$-35-\mathrm{a}$ \\
$-35-\mathrm{b}$ \\
Volume \\
$\circ 0.5$ \\
$\circ 1$ \\
O 2 \\
\hline
\end{tabular}
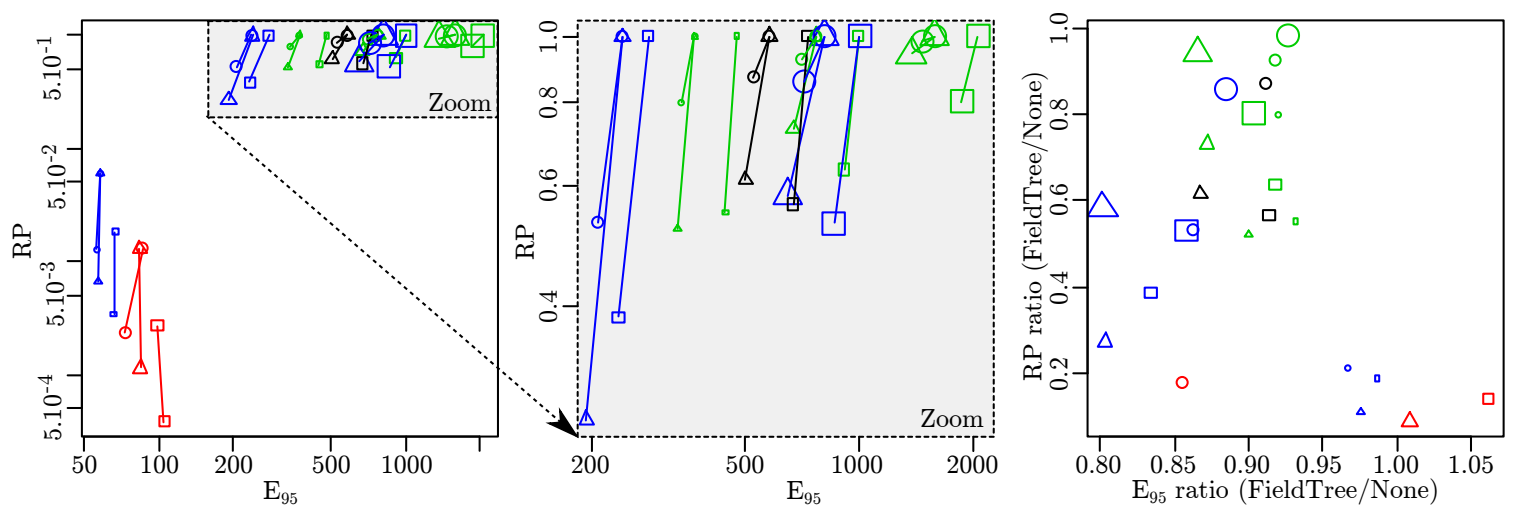

Fig. 6 Left and middle: values of reach probability $R P$ and of the $95^{\text {th }}$ percentile of rock energy $E_{95}$ for the scenarios with (FieldTree) and without forest (None). Symbol type depicts the study area, size depicts the rock volume and colour the terrain conditions. Lines link the corresponding FieldTree and None scenarios. Right: the symbols are similar but the ratios of values for the FieldTree and None scenarios are represented

In Saint-Agnan, the LidarArea and LidarCombi result in an underestimation of $R P$ for soil $b$. With soil type $a$, the $R P$ value is closer to the FieldTree reference, but $E_{95}$ is underestimated. The FieldArea scenario yields a slight overestimation of $R P$ and an underestimation of $E_{95}$ in all cases.

In Saint-Paul, the LidarArea and LidarCombi also result in an underestimation of $R P$ for soil $b$, except when rock volume is $2 \mathrm{~m}^{3}$. Otherwise, all scenarios except the LidarTree are very close to the reference $R P$. The FieldArea generally results in a slight underestimation of $E_{95}$, but to a lesser extent than with the LidarCombi scenario.

In Valdrome, $R P$ tends to be overestimated, while the $E_{95}$ is within $96 \%$ and $107 \%$ of the FieldTree value. Contrary to Saint-Agnan, the points in Fig. 7 are grouped by terrain type rather than by scenario, which shows that data source for the forest input has less impact on the quantification of the forest protection effect than the terrain type.

\section{Discussion}

5.1 Influence of rockfall event characteristics on forest protection effect

The results obtained with three small contrasted forest stands show that the forest protection effect depends mostly on the terrain and rock volume.

When the topography and rock volume yield small energies of falling rocks, typically lower than $200 \mathrm{~kJ}$, the tree impact probability and the amount of dissipated energy allow to stop a significant proportion of rocks. Rocks which pass through the forest are those which have not impacted any tree, so that $E_{95}$ is not reduced. Silviculture guides in Switzerland (Dorren et al 2014) and France (Ancelin et al 2006) stand that the length of a forest should be greater than $250 \mathrm{~m}$ to ensure a significant protection effect. For example, considering that if $20 \%$ of rocks go through a $50 \mathrm{~m}$ long stand without any impact, then the proportion would theoretically be $0.2^{5}=0.032 \%$ in a stand of $250 \mathrm{~m}$.

When rock energies are larger, the number of tree impacts and the amount of dissipated energy are not sufficient to stop a large proportion of rocks. However, the value of $E_{95}$ is slightly reduced. Indeed, rocks with larger size have a greater probability to impact trees which entails slight reduction of their energy.

From a more general point view, it turns out that the forest integration has a much smaller influence on rockfall intensity and frequency values than rock volume, soil type, and terrain slope values. For example, $E_{95}$ in Saint-Agnan is $998 \mathrm{~kJ}$ with $35^{\circ}$ slope, soil type $a$ and $1 \mathrm{~m}^{3}$ volume, but $478 \mathrm{~kJ}$ with $0.5 \mathrm{~m}^{3}$ and $2060 \mathrm{~kJ}$ with $2 \mathrm{~m}^{3}$. The value for $1 \mathrm{~m}^{3}$ decrease to $280 \mathrm{~kJ}$ if soil type is $b$. The variations are larger than a factor 2 , whereas when forest is taken into account, the $E_{95}$ is $92 \%$ of the value without forest. The accurate assessment of rock volume and soil properties is thus essential for rockfall hazard assessment purposes, included when forest effects are integrated. In the case of low energy rockfall events, the influence of forest could nonetheless be of higher importance when the length of the forest is sufficient.

\subsection{Suitability of Lidar data for the evaluation of forest protection effect}

Whatever the input data, it turns out that the forest protection effect is quite well estimated at the small stand scale, with $E_{95}$ within $\pm 15 \%$ of the forest field data reference and reach probability within a factor 2 . 

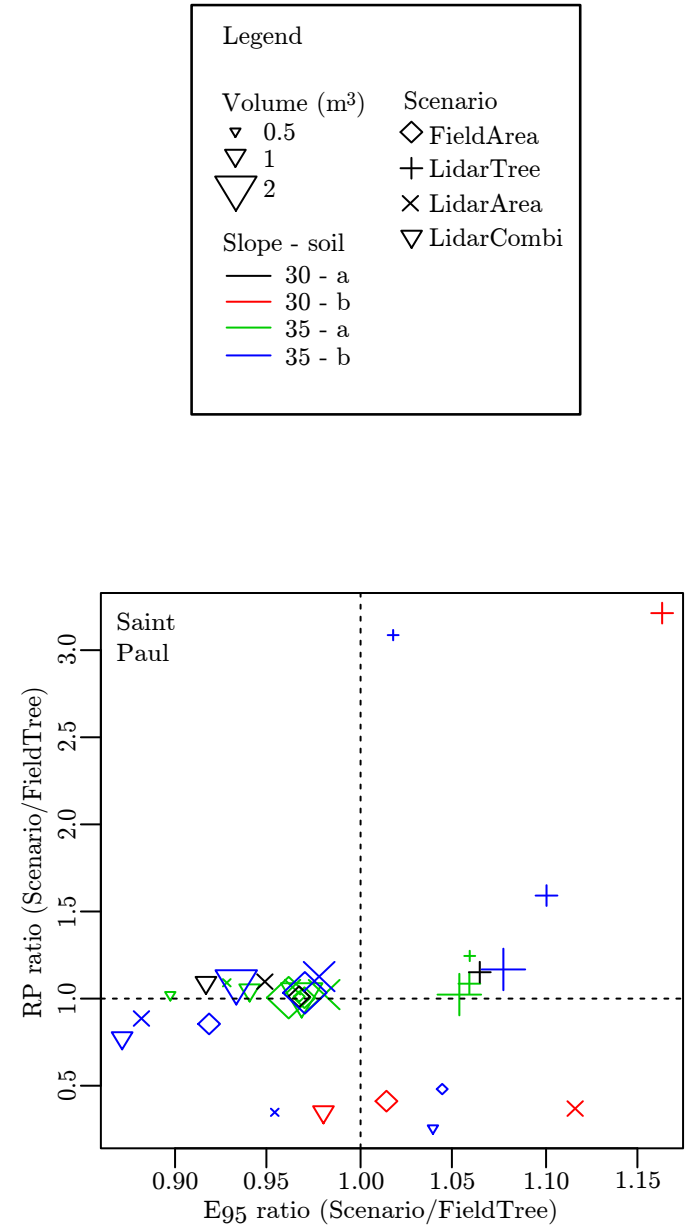

Fig. 7 Scatter plot of reach probability $R P$ and the $95^{\text {th }}$ percentile of rock energy $E_{95}$ for the different scenarios, expressed as ratio to the FieldTree scenario. Symbol type refers to the forest input data scenario, colour to the terrain parameters and symbol size to rock volume

Indeed, those values are smaller than the order of magnitude of the effect of the terrain parameters, and of classes for rockfall hazard zonation. For example, in Switzerland (Raetzo et al 2002) the low, medium and high intensity intervals for mass movements are defined by the thresholds 30 and $300 \mathrm{~kJ}$ (10 factor). The return periods for the low, medium and high probability categories are 1 to 30 years, 30 to 100 and 100 to 300 (3 factor). In France (Berger et al 2014) the categories are based on the reach probability thresholds of $10^{-6}, 10^{-4}$ and $10^{-2}$ (100 factor).

\subsubsection{Lidar area-based method}

The forest protection effect is slightly overestimated when using LidarArea method in Saint-Agnan and SaintPaul, while the error is lower in Valdrome. Indeed, the LidarArea method leads to an over-estimation of stem density, whereas the mean diameter is better estimated.
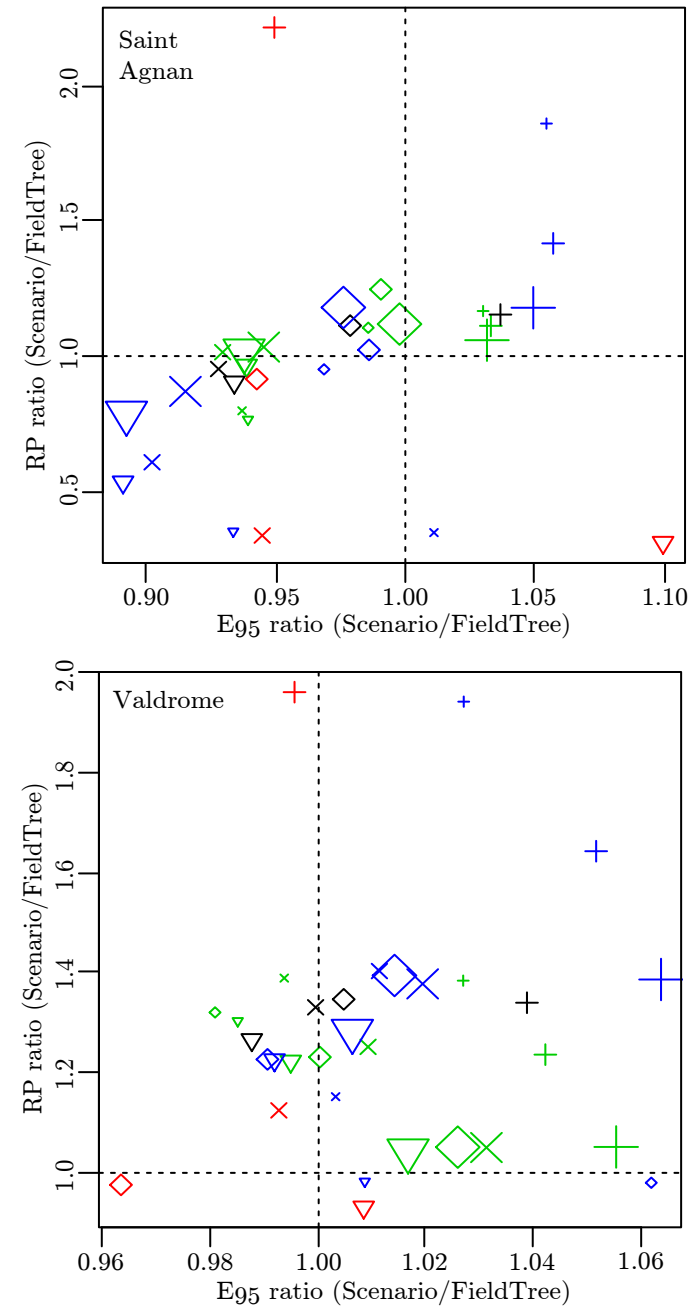

In Valdrome the model is calibrated with the large plot data themselves which explains why the error is lower. The estimation errors regarding the diameter distribution and stem density then impact the rockfall simulations. If the Lidar model is correct, then the forest estimates are unbiased (McRoberts 2010), but the assessment of the propagation of local errors in rockfall simulations at the hillside scale requires additional investigations.

The accuracy of the Lidar area-based prediction models is comparable to previous studies. With 37 plots in a mixed forest of Bavaria, Heurich and Thoma (2008) obtained a coefficient of variation of the root mean square error of $25.3 \%$ with a $\mathrm{R}^{2}$ of 0.80 for stem density. The values are $17.9 \%$ and 0.57 for mean diameter. In Saint Agnan, accuracy is similar for stem density. For mean diameter the $\mathrm{R}^{2}$ is higher but the error is also larger. This is due to the presence of two outliers which are open forests with large trees in pastures. When those 
plots are removed from the validation set, the RMSE decreases to $16.4 \%$, with a $\mathrm{R}^{2}$ of 0.64 . The area-based method is theoretically unbiased, but the errors can be locally important, as shown here in Saint-Agnan and Saint-Paul.

\subsubsection{Lidar single tree detection}

Because the suppressed trees and some co-dominants are not detected, the forest protection effect is underestimated when the local maxima are used as input trees for the simulations. Indeed, the detected stem density is smaller than the real one. The detection algorithm is set to avoid the commissions errors even tough it limits the detection rate. Indeed it is not advisable to allow too many commission errors as their number depends on the forest structure (Eysn et al 2015) and is almost impossible to evaluate when no field data are available.

In the coppice stand of Saint-Paul, the very low detection rate yields a large under-estimation of the forest protection effect. Indeed, a clump has one crown but several stems, so that the detection of local maxima leads to the detection of clumps rather than stems themselves (Fig. 4). In Valdrôme almost all trees are detected in sparse areas, but in denser areas the proportion decreases (Fig. 8).

The computation of the diameter from the detected height might slightly balance the under-estimation of stem density in our sites. The heights of the taller trees are over-estimated because trees are tilted downslope (Hirata et al 2004). Applying a diameter-height relationship calibrated with field measured heights thus leads to over-estimated diameters. It would be better to calibrate height estimation models directly with Lidarderived metrics (e.g. height, crown surface) in order to limit bias, but this requires site-specific Lidar and treelevel field data. Species-specific relationships should also be considered but this supposes that species are previously determined.

\subsubsection{Combined scenario}

The combination of the area-based stem density and diameter distribution with the position of the detected trees and the forest mask obtained from single tree detection does not improve much forest protection effect assessment compared to the basic area-based scenario in all cases, except for a tiny decrease in both $E_{95}$ and $R P$.

In Valdrome, the LidarCombi scenario has a slightly lower variability than the LidarArea scenario when the workflow is repeated 30 times. This demonstrates that existing canopy gaps should be taken into account for a more precise quantification of forest protection effect. Even tough this error source seems minor compared to the errors in stem density and mean diameter estimation, it may have a greater effect in whole hillsides were unforested rockfall channels are present. Besides, canopy gaps will influence the spatial distribution of rockfall, which was not investigated here.

5.3 Perspectives for improving the evaluation of rockfall protection effect of forests using Lidar data

\subsubsection{Deciduous and coniferous trees proportions}

The assessment of the proportion of coniferous trees is important as the energy dissipation by broadleaved trees is 1.7 times higher than for coniferous trees (Dorren 2015). This issue of the coniferous percentage is exemplified by the comparison of the FieldTree and Fiel$d$ Area scenarios in the mixed stand of Saint-Agnan. Indeed, the proportion of passing rocks is over-estimated. The major difference between those scenarios is that the average of the coniferous percentage over large pixels (40 m width) is used for the FieldArea scenario (Monnet and Bourrier 2014).

In our study, the raster cell size for the simulation is two meters, so that it was possible to rasterise the coniferous percentage to the tree level. In case rockfalls are simulated at a coarser resolution, such as 5 or $10 \mathrm{~m}$, modelling species distribution by a coniferous percentage value entails that the diameter distribution is the same for deciduous and coniferous trees, which is seldom true.

For the FieldTree scenario, a better integration of species effect could consists of weighting the coniferous proportion by diameter. In field inventories it is not more costly to count the specie-dependant diameter distribution than to measure diameters and count species independently.

In the case of a Lidar-based field inventory, some studies have shown that coniferous can be distinguished from broadleaved trees (Lindberg et al 2014) for the detected trees. In addition, the proportion can be estimated at the stand level thanks to fusion with optical data (Hamid et al 2004; Cipar et al 2004). Combining both approaches would be interesting in order to derive species-specific diameter and spatial distributions.

\subsubsection{Tree position and diameter}

Another potential improvement for modelling forest effects is related with the modelling of tree diameter distribution. For the FieldArea and LidarArea scenarios, 
the diameter distribution is reconstructed using a twoparameters Gamma distribution model, which alters the shape of the distribution and fails to handle the case of bi-modal distributions. Besides, the interval of the Gamma distribution is [0,+inf[, so that small diameters can be generated below the diameter limit used for the inventory and very large diameters may occur.

Field inventories generally provide the diameter distribution, and recent studies have demonstrated the possibility to estimate diameter percentiles from Lidar data (Bollandsås et al 2013). The rockfall simulation software could be improved by using a tree distribution defined by several percentiles rather than by the mean and standard deviation.

The uniform sampling of the spatial distribution of trees may also lead to different rockfall propagation estimations. The coppice data exhibit a clustered pattern that is not accounted for by the uniform sampling of positions. Recent works show that this tree-level aggregation has no or limited effect on rockfall propagation (Radtke et al 2014).

In the Valdrôme stand, there is no aggregation but the stem density is not spatially homogenous inside the pixels considered in the FieldArea scenario. The density is higher near the upper border of the plot (Fig. 8). This pattern is not accounted for in the generated positions. Considering that the diameter distributions are similar, this difference in spatial heterogeneity might explain why the $E_{95}$ value is similar but with $20-40 \%$ more passing rocks in the case of the FieldArea scenario. Indeed in the FieldTree case, there are higher chances that a sufficient number of consecutive tree impacts lead to a stop in the upper part. The integration of the spatial heterogeneity of stem density within the forest stands is thus another important factor regarding the assessment of rockfall propagation. When the canopy gaps are taken into account (LidarCombi scenario), the reach probability is only slightly decreased. However, the gaps in this area are smaller than $10 \mathrm{~m}$. Recommendations in protection forests are to limit gap size to 1.5 times the dominant height Ancelin et al 2006). For example the gap could be up to $30 \mathrm{~m}$ wide when the largest trees are only $20 \mathrm{~m}$ high.

\section{Conclusion}

This study at the stand level identifies some limitations and challenges regarding the integration of forest data for rockfall hazard assessment. The simulations implemented in three small forest stands confirm that forest protection is significant when rockfall energies are not too important and when forest length ensure that tree impacts occur. Those findings are consistent with the management recommendations based on empirical knowledge. Considering the other parameters influencing rockfall propagation, such as soil type and rock volume, and the practitioners current classification, the forest protection effect can be satisfactorily estimated with airborne Lidar data, particularly regarding the intensity ( $95^{\text {th }}$ percentile of rock energy). In particular, the detection method lead to conservative estimates and is easily applicable when the Lidar point density is sufficient. The area-based method requires calibration data but should allow unbiased estimations for large areas.

Recent advances in the modelling of diameter distributions from Lidar data require that rockfall simulation softwares integrate some percentile-based input distribution. The issue of specie-specific diameter distribution still requires some investigations but seems important in the case of mixed stands.

The reach probability estimation could be improved by a better integration of the spatial distribution of trees, as results show that canopy gaps and intra-forest heterogeneity of stem density influence the rockfall progation. However limits of both methods could be quickly reached, as tree detection results depend on the forest structure and as the resolution for the area-based method is around $20 \mathrm{~m}$.

Those findings obtained for forest stands have yet to be confirmed at the hillside scale in real-case study. In particular the combination of forest features (spatial distribution of stem density and diameter) with topographic features such as channels and ridges probably yields specific pattern in the spatial distribution of rockfall intensity and frequency.

\section{References}

Ancelin P, Barthelon C, Berger F, Cardew M, Chauvin C, Courbaud B, Descroix L, Dorren L, Fay J, Gaudry P, Gauquelin X, Genin JR, Joud D, Loho P, Mermin É, Plancheron F, Prochasson A, Rey F, Rubeaud D, Wlérick L (2006) Guide des sylvicultures de montagne: Alpes du Nord françaises. Cemagref-ONF

Berger et al (2014) Méthodologie de l'élaboration d'un volet aléa rocheux d'un PPRN. Technical report of Irstea, BRGM, CETE, DGPR, DDT 0638 74, IFSTTAR, ONFRTM. Ed: French Ministry of Environment. 49 p.

Bigot C, Dorren L, Berger F (2009) Quantifying the protective function of a forest against rockfall for past, present and future scenarios using two modelling approaches. Nat Hazards 49(1):99-111

Bollandsås OM, Maltamo M, Gobakken T, Næsset E (2013) Comparing parametric and non-parametric modelling of diameter distributions on independent data using airborne laser scanning in a boreal conifer forest. Forestry 86(4):493-501, DOI 10.1093/forestry/cpt020

Breidenbach J, Næsset E, Lien V, Gobakken T, Solberg S (2010) Prediction of species specific forest inventory at- 

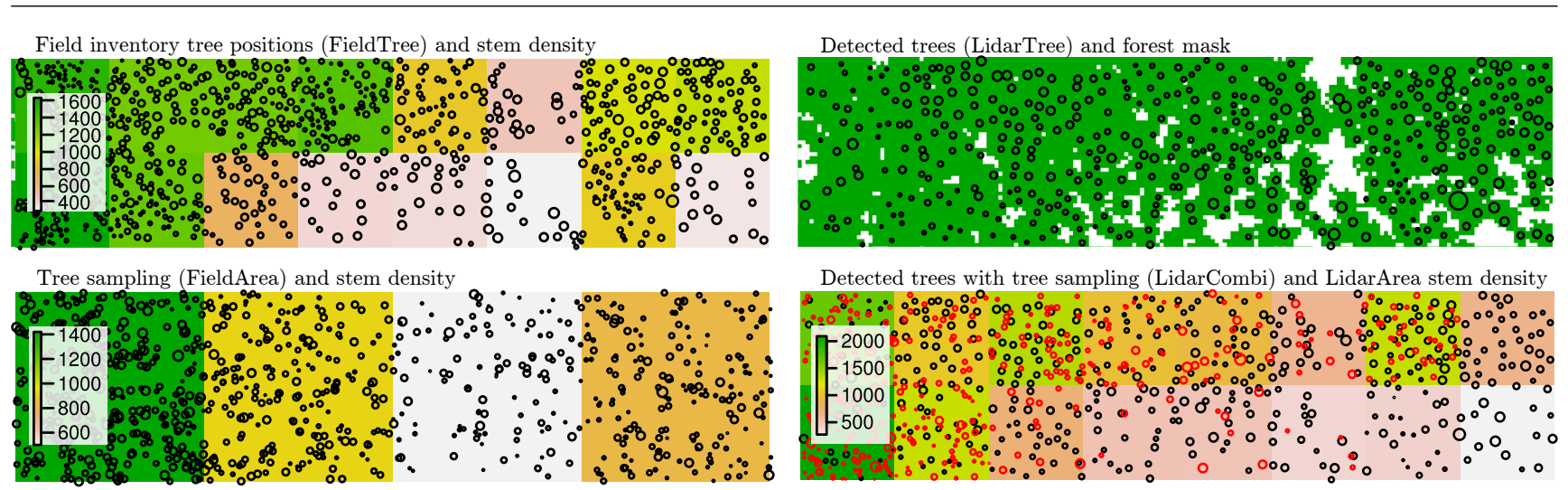

Detected trees with tree sampling (LidarCombi) and LidarArea stem density

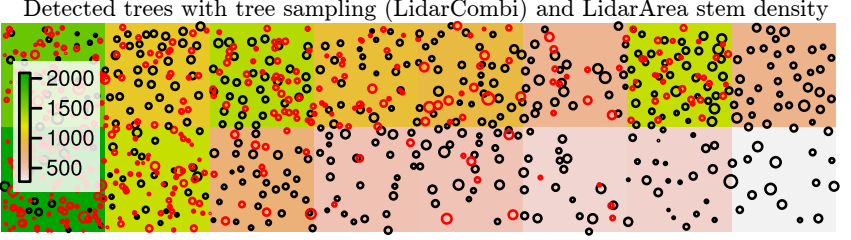

Fig. 8 Valdrôme site: trees positions (black dots, size proportional to diameter) and stem density (background) for four scenarios. Background of the LidarTree scenario is the Lidar forest mask. Red dots in LidarCombi are the sampled trees, whereas black dots are the detected maxima

tributes using a nonparametric semi-individual tree crown approach based on fused airborne laser scanning and multispectral data. Remote Sens Environ 114(4):911-924

Ciabocco G, Boccia L, Ripa MN (2009) Energy dissipation of rockfalls by coppice structures. Nat Hazards Earth Syst Sci 9(3):993-1001

Cipar J, Cooley T, Lockwood R, Grigsby P (2004) Distinguishing between coniferous and deciduous forests using hyperspectral imagery. In: Geoscience and Remote Sensing Symposium, 2004. IGARSS'04. Proceedings. 2004 IEEE International, vol 4, pp 2348-2351, DOI 10.1109/ IGARSS.2004.1369758

Dorren L (2015) Rockyfor3D (v5.2) revealed - Transparent description of the complete 3D rockfall model. ecorisQ. http://www.ecorisq.org/publications

Dorren L, Berger F, Frehner M, Huber M, Kühne K, Métral R, Sandri A, Schwitter R, Thormann JJ, Wasser B (2014) Das neue NaiS-anforderungsprofil steinschlag. Schweiz Z Forstwes 166(1):16-23, DOI 10.3188/szf.2015.0016

Dorren L, Berger F, Le Hir C, Mermin É, Tardif P (2005) Mechanisms, effects and management implications of rockfall in forests. For Ecol Manage 215(1-3):183-195

Dorren L, Berger F, Putters US (2006) Real-size experiments and 3-D simulation of rockfall on forested and nonforested slopes. Nat Hazards Earth Syst Sci 6(1):145-153

Eysn L, Hollaus M, Lindberg E, Berger F, Monnet J-M, Dalponte M, Kobal M, Pellegrini M, Lingua E, Mongus D, Pfeifer N (2015) A benchmark of Lidar-based single tree detection methods using heterogeneous forest data from the Alpine Space. Forests 6(5):1721-1747, DOI $10.3390 /$ f6051721

Hamid JA, Mather PM, Hill RA (2004) Mapping of conifer forest plantations using airborne hyperspectral and Lidar data. Remote Sensing in Transition pp 185-190

Heurich M, Thoma F (2008) Estimation of forestry stand parameters using laser scanning data in temperate, structurally rich natural European beech (Fagus sylvatica) and Norway spruce (Picea abies) forests. Forestry 81(5):645661, DOI 10.1093/forestry/cpn038

Hirata Y, Sato K, Kuramoto S, Sakai A (2004) Extracting forest patch attributes at the landscape level using new remote sensing techniques - an integrated approach of high-resolution satellite data, airborne Lidar data and GIS data for forest conservation. EFI Proceedings (No.51):359-367
Hollaus M, Dorigo W, Wagner W, Schadauer K, Höfle B, Maier B (2009) Operational wide-area stem volume estimation based on airborne laser scanning and national forest inventory data. Int J Remote Sens 30(19):5159-5175, DOI 10.1080/01431160903022894

Holopainen M, Vastaranta M, Hyyppä J (2014) Outlook for the next generation's precision forestry in finland. Forests 5(7):1682-1694, DOI 10.3390/f5071682

Jancke O, Dorren L, Berger F, Fuhr M, Köhl M (2009) Implications of coppice stand characteristics on the rockfall protection function. For Ecol Manage 259(1):124-131

Kaartinen H, Hyyppa J, Yu XW, Vastaranta M, Hyyppa H, Kukko A, Holopainen M, Heipke C, Hirschmugl M, Morsdorf F, Næsset E, Pitkanen J, Popescu S, Solberg S, Wolf BM, Wu JC (2012) An international comparison of individual tree detection and extraction using airborne laser scanning. Remote Sens 4(4):950-974

Lindberg E, Holmgren J, Olofsson K, Wallerman J, Olsson H (2010) Estimation of tree lists from airborne laser scanning by combining single-tree and area-based methods. Int J Remote Sens 31(5):1175-1192

Lindberg E, Eysn L, Hollaus M, Holmgren J, Pfeifer N (2014) Delineation of tree crowns and tree species classification from full-waveform airborne laser scanning data using 3D ellipsoidal clustering. IEEE J Sel Top Appl Earth Observ Remote Sens 7(7):3174-3181, DOI 10.1109/JSTARS. 2014.2331276

McRoberts RE (2010) Probability- and model-based approaches to inference for proportion forest using satellite imagery as ancillary data. Remote Sens Environ 114(5):1017-1025

Monnet J-M, Mermin E, Chanussot J, Berger F (2010a) Estimation of forestry parameters in mountainous coppice stands using airborne laser scanning. In: Proceedings of Silvilaser 2010, 10th International Conference on Lidar Applications for Assessing Forest Ecosystems, Freiburg, Germany, Sept. 14-17, pp 109-116

Monnet J-M, Mermin E, Chanussot J, Berger F (2010b) Tree top detection using local maxima filtering: a parameter sensitivity analysis. In: Proceedings of Silvilaser 2010, 10th International Conference on Lidar Applications for Assessing Forest Ecosystems, Freiburg, Germany, Sept. $14-17$, pp 460-468

Monnet J-M, Bourrier F (2014) Evaluation of the effect of forest input data on rockfall simulations. In: Proceedings of the Interpraevent 2014 International Symposium on 
Natural Disaster Mitigation to Establish Society With Resilience, Nara, Japan, Nov. 25-28, 8 p

Monnet J-M, Chirouze É, Mermin É (2015) Estimation de paramètres forestiers par données Lidar aéroporté et imagerie satellitaire RapidEye : Étude de sensibilité. Revue Française de Photogrammétrie et Télédétection, 211212:71-80

Munoz A, Bock J, Monnet J-M, Renaud JP, Jolly A, Riond C (2015) Évaluation par validation indépendante des prédictions des paramètres forestiers réalisées à partir de données LiDAR aéroporté. Revue Française de Photogrammétrie et Télédétection, 211-212:81-92

ONF (2012) Plan de gestion forestière contre les chutes de blocs. Forêt domaniale du Val de Drôme. Technical report Interreg project Manfred, 2009-2012. 14 p.

Næsset E (2002) Predicting forest stand characteristics with airborne scanning laser using a practical two-stage procedure and field data. Remote Sens Environ 80(1):88-99, DOI 10.1016/S0034-4257(01)00290-5

Perret S, Dolf F, Kienholz H (2004) Rockfalls into forests: Analysis and simulation of rockfall trajectories - considerations with respect to mountainous forests in Switzerland. Landslides 1(2):123-130

Peuhkurinen J, Mehtatalo L, Maltamo M (2011) Comparing individual tree detection and the area-based statistical approach for the retrieval of forest stand characteristics using airborne laser scanning in scots pine stands. Can J For Res 41(3):583-598

Radtke A, Toe D, Berger F, Zerbe S, Bourrier F (2014) Managing coppice forests for rockfall protection: lessons from modeling. Ann For Sci 71(4):485-494

Raetzo H, Lateltin O, Bollinger D, Tripet J (2002) Hazard assessment in switzerland - codes of practice for mass movements. Bull Eng Geol Environ 61(3):263-268

Stoffel M, Schneuwly D, Bollschweiler M, Lièvre I, Delaloye R, Myint M, Monbaron M (2005) Analyzing rockfall activity (1600-2002) in a protection forest - a case study using dendrogeomorphology. Geomorphology 68(3-4):224-241

Vauhkonen J, Ene L, Gupta S, Heinzel J, Holmgren J, Pitkanen J, Solberg S, Wang Y, Weinacker H, Hauglin KM, Lien V, Packalen P, Gobakken T, Koch B, Næsset E, Tokola T, Maltamo M (2012) Comparative testing of single-tree detection algorithms under different types of forest. Forestry 85(1):27-40

White J, Wulder M, Varhola A, Vastaranta M, Coops N, Cook B, Pitt D, Woods M (2013) A best practices guide for generating forest inventory attributes from airborne laser scanning data using an area-based approach

Xu Q, Hou Z, Maltamo M, Tokola T (2014) Calibration of area based diameter distribution with individual tree based diameter estimates using airborne laser scanning. ISPRS J Photogramm Remote Sens 93:65-75, DOI 10.1016/j.isprsjprs.2014.03.005 